\title{
Analysis and Reflections on the Third Learning Analytics and Knowledge Conference (LAK 2013)
}

\author{
Xavier Ochoa \\ Escuela Superior Politécnica del Litoral, Ecuador \\ xavier@cti.espol.edu.ec \\ Dan Suthers \\ University of Hawai'i at Manoa, USA \\ Katrien Verbert \\ Vrije Universiteit Brussel and University of Leuven, Belgium \\ Erik Duval \\ University of Leuven, Belgium
}

\begin{abstract}
Analyzing a conference, especially one as young and focused as LAK, provides the opportunity to observe the structure and contributions of the scientific community around it. This work will perform a Scientometric analysis, coupled with a more in-depth manual content analysis, to extract this insight from the proceedings and program of LAK 2013. Authorship analysis reveals an open and international community, while internal citation analysis provides evidence of the construction of a body of knowledge central to Learning Analytics. The analysis of the content of the papers found five main topics: visualization, behaviour analysis, social learning analytics, learning analytics for MOOCs, and learning analytics issues (ethical, scalability, etc.), as well as papers reflecting on the field itself. We discuss representative papers presented at the conference, highlighting trends and new developments. Learning analytics is a diverse multidisciplinary field with an emerging interdisciplinary core, well situated to benefit from productive dialogue concerning its scope and purpose and to reflect on the pedagogies and epistemologies implied by its methods.
\end{abstract}

Keywords: Scientometrics, conference review, learning analytics

\section{INTRODUCTION}

Learning Analytics is a new, expanding field that grows at the confluence of learning technologies, educational research, and data science. From early works, such as Tinto's (1993) study on factors affecting the persistence of college students, to field-defining expositions, such as Siemens and Long (2011) and Campbell et al.'s (2007) work on Academic Analytics, to the current papers in this special issue, researchers and practitioners with different backgrounds and methodologies have tried to solve two simple but challenging questions: How do we measure the important characteristics of the learning process? And how do we use those measurements to improve it?

To assemble this disparate group of researchers and practitioners, the first Learning Analytics and Knowledge (LAK) conference was organized in 2011 in Banff, Alberta, Canada. This first event, with only 27 presentations and 34 different authors, served as the nucleus for what is now the Learning Analytics 
community. The success of this event led to the organization of LAK 2012 in Vancouver, British Columbia, Canada, this time with 52 presentations and 140 authors. LAK 2012 recognized the existence of the community and set the basis for an annual conference in the field. The articles presented in this special issue belong to the third iteration of this community meeting, LAK 2013, organized in Leuven, Belgium. The focus of this third year was Learning Analytics as a "middle-space" where different disciplines could exchange visions, ideas, and methodologies to improve learning through a deep understanding of the processes in which students, instructors, and institutions are involved.

As a transition point from a fledgling to a consolidated community, LAK 2013 provides a snapshot of the history of Learning Analytics. The goal of this issue of the journal is to provide an overview of the composition and content of the LAK 2013 program. This overview will be conducted in two ways: 1) a Scientometric analysis of the articles published in LAK '13, and 2) a review of the content of representative conference papers. Our conclusions will highlight the main findings of these two approaches.

\section{SCIENTOMETRIC ANALYSIS}

All published scientific endeavours leave traces susceptible to quantitative analysis in order to gain a better understanding of epistemological phenomena occurring in the scientific field. Co-authorship and bibliographical coupling networks could provide insight into the nature of the scientific community and how the individuals in it influence each other (Kessler, 1963). Text processing of the content of the scientific papers could provide evidence for the emergence or disappearance of research topics and concepts from the research field (Ding, Chowdhury, \& Foo, 2001). Simple statistics about the authors and their papers can provide an indication of the reach, diversity, and "health" of the community of scientists and practitioners interested in the field. This type of analysis is commonly known as Bibliometrics (when related only to the documents produced by research) or more generally as Scientometrics (when the focus is the research community and the knowledge building process) (Hood \& Wilson, 2001). In this section, we study the LAK 2013 program through the Scientometric lens. The rest of this section will provide a quantitative analysis of the status of Learning Analytics research as presented at LAK 2013.

\subsection{Authorship Analysis}

The first step in understanding the authorship of LAK 2013 is to obtain simple statistics regarding the author distribution of the papers presented at LAK 2013:

Basic Quantities: LAK 2013 had an approval rate of $28 \%$ for full papers (58 submitted, 16 accepted) and an approval rate of $22 \%$ for short papers (36 submitted, 8 accepted) without counting 14 full papers accepted as short. By comparison, the acceptance rate for full papers for LAK 2011 and LAK 2012 was $45 \%$ and 39\% respectively. The LAK 2013 proceedings contained 47 documents (16 full papers, 22 short papers, 2 design briefs, 4 workshops, 2 panels, and 1 note from the editors). A total of 143 authors produced those documents.

New and Returning Authors: At LAK 2011, there were 34 authors. Of those, 30 returned to LAK 2012, together with 110 new authors, expanding the community to 140 individuals. At LAK 2013, there were 41 returning authors from LAK 2011 (4), 2012 (17), or both (20). At LAK 2013, the community annexed 102 
new authors.

Authorship distribution: How prolific an author is can be measured by how many papers he or she has been involved in. In the case of LAK '13, the most prolific authors are Simon Buckingham Shum (5 documents), Peter Reimann, Rebecca Ferguson, and Ryan Baker (3 documents each). If their contributions are weighted (the weight of a paper is the inverse of the number of authors), the list changes to Paulo Blikstein (1.5 papers), Simon Buckingham Shum (1.075 papers), Andreas Harrer, Doug Clow, and June Ahn (1 paper each). The distribution is very flat, with no author actually dominating the scene. This evidence, together with the fact that most of the authors were new to LAK, suggests that Learning Analytics is still an open community where interested researchers can be included without being part of a closed "academic club."

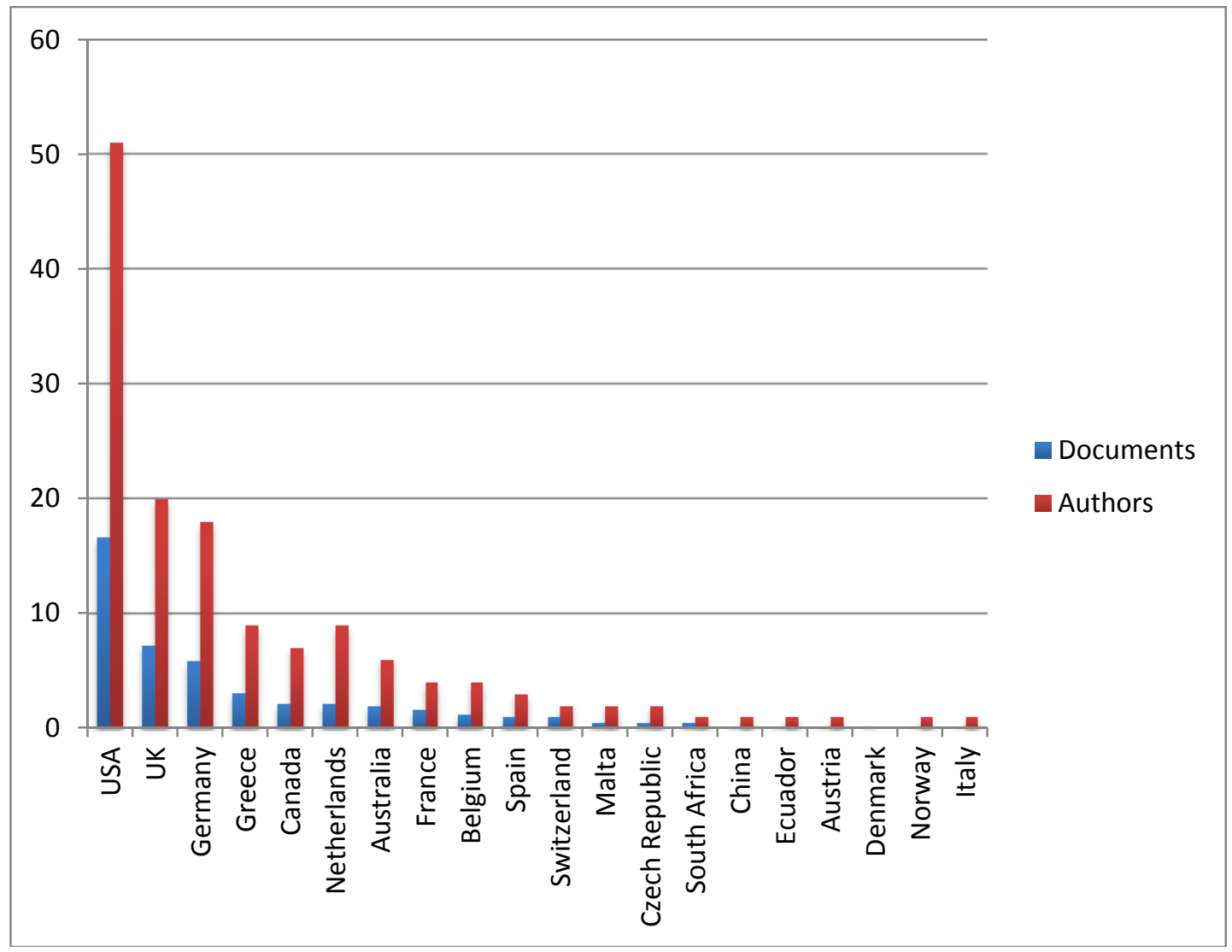

Figure 1. Country Distribution by Authors and Documents

Geographical Distribution: To calculate the geographical distribution, two measurements were considered: contribution by author and contribution by document. The first was calculated simply by the number of different authors affiliated with each country. The second was calculated by the weighted contribution of each author (each paper weight as the inverse of the number of authors). The top countries for the first measurement were USA (51 authors), UK (20 authors), Germany (18 authors), and Greece and Netherlands (9 authors each). For the second metric, the top countries do not vary much: USA (16.65 papers), UK (7.275 papers), Germany (5.9 papers), Greece (3.05 papers) and Canada (2.2 papers). A continental view shows the following results: Europe contributed with 76 authors, North America with 58, Oceania with 6 and Asia, South America, and Africa with 1 author each. A full graph of 
the distribution (Figure 1) presents a conference still dominated by the main research players worldwide: USA, West and Central Europe, Canada, and Australia. While small contributions are present from Latin America and Africa, there is a notable absence of Asian contributors.

Career Length Distribution: The length of the research career of each author was estimated using the date of first publication as recorded by the ACM Digital Library. While this data under-represents the career length of researchers in the field of education, the values obtained offer a general indication of distribution of seniority. For the 143 authors, the distribution was as follows: 28 senior researchers ( $>=15$ years), 45 junior researchers (<=14 years and $>4$ years) and $70 \mathrm{Ph}$.D. students or initial stage researchers ( $<=4$ years). This distribution reflects the pyramidal structure of most scientific groups (see Figure 2).

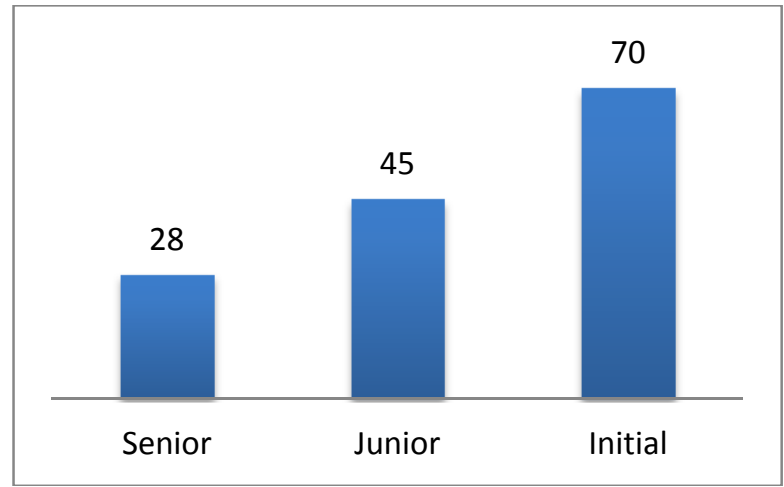

Figure 2. Distribution of Career Length

Sector Distribution: Authors were classified in three sectors (Academia, Research, and Industry) according to their affiliation. The results show that 128 authors belong to academic institutions, 8 to research centres, and 7 to companies. LAK '13 can be clearly classified as a research-oriented conference.

Additional information about the Learning Analytics community can be extracted from how different individuals collaborate in order to produce research. The following is a series of collaboration indicators:

Authors per Paper: The average is 3.44 authors, which means that LAK 2013 publications usually needed a team of at least three people. This result maintains when the distribution of authors per paper is analyzed (Figure 3). Teams of two, three, four, and five individuals produced most of the papers rather than single authors.

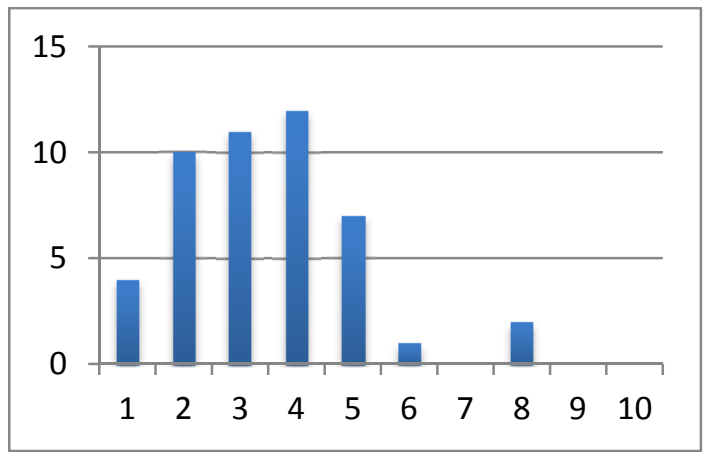

Figure 3. Distribution of Authors per Paper 
Institutional Collaboration: We consider a paper inter-institutional if its authors are affiliated with more than one institution from the same country. We consider a paper international if its authors are affiliated with at least two institutions in different countries. Analysis of the collaboration shows that, of the 47 documents, 14 (30\%) were international, 8 (17\%) were inter-institutional, and $25(53 \%)$ were produced by authors of a single institution. These values reflect the current percentage of collaboration in science (Leydesdorff \& Wagner, 2008).

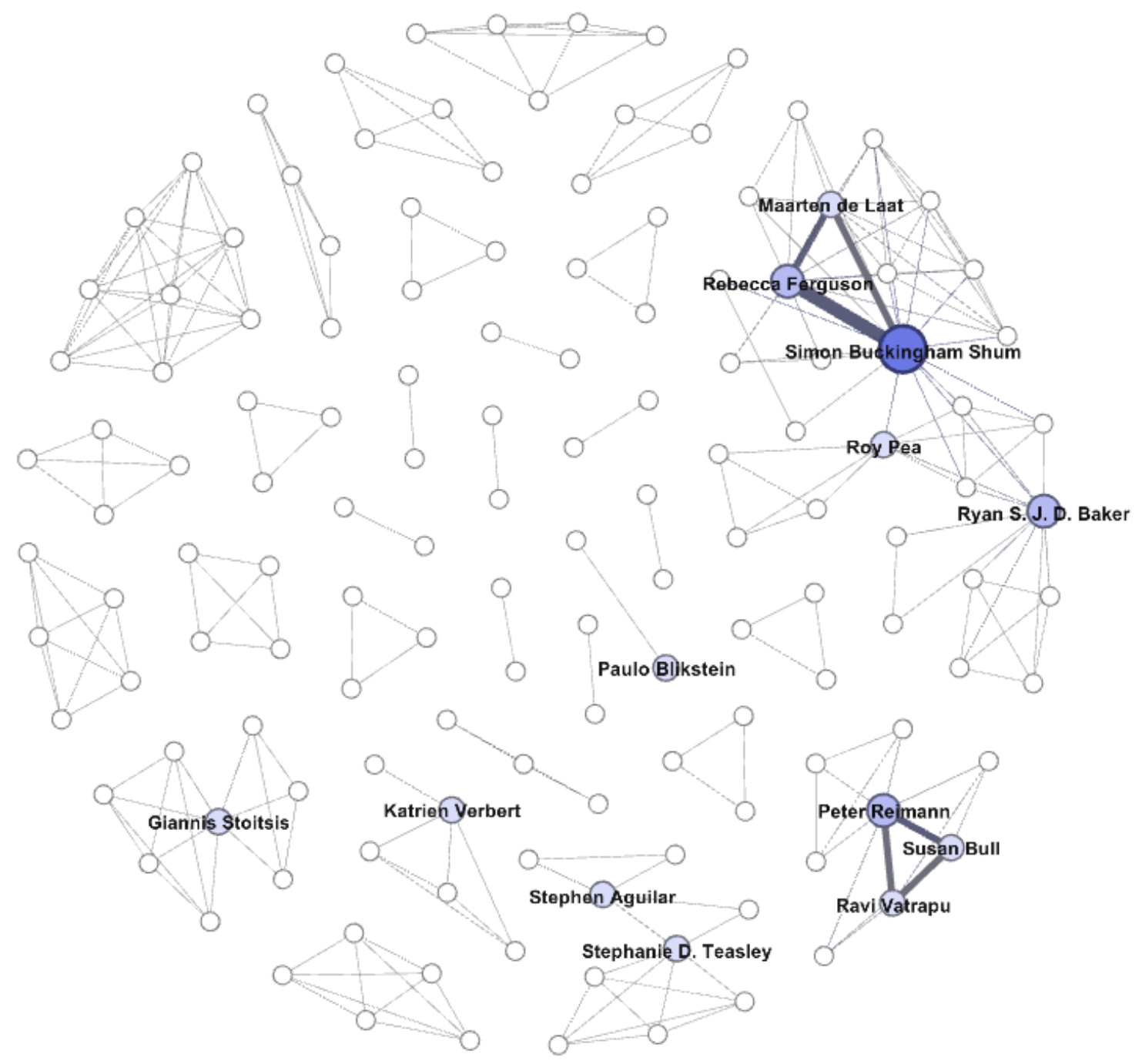

Figure 4. Co-Authorship Network: Size and colour represent the number of published papers from LAK 2013

Co-authorship Network: A useful way to visualize the author community is to draw a co-authorship network. In this network, each node is an LAK '13 author and each line is a link between co-authors. The strength of the line depends on the number of LAK '13 papers that the two authors have co-authored (see Figure 4). Most authors, the authors of individual papers, congregate in small cliques. It is interesting to note, however, that a more intricate collaboration network interconnects several important LAK '13 authors. Simon Buckingham Shum, Rebecca Ferguson, Roy Pea, Maarten de Laat, and 
Ryan Baker are part of this sub-network. Other small nuclei of collaboration surround Stephanie Teasley and Peter Reimann. A parallel analysis of all Learning Analytics literature conducted by Dawson, Gašević, Siemens, and Joksimovic (2014) found a similar network configuration.

\subsection{Internal Citation Analysis}

Scientific papers are not isolated entities; each new paper is linked to previous papers through citations. It is possible to gain insight on the main sources of knowledge in a field through the analysis of which papers and authors are the most referenced and how different papers may be similar based on their number of references in common. The following provides a basic quantitative analysis for the references contained in the LAK ' 13 papers:

Basic Quantities: LAK 2013 documents had a total of 929 references, with an average of 21 bibliographic entries per paper, suggesting that the LAK papers draw knowledge from a large number of sources.

Shared References: The references present in LAK 2013 documents were directed to 819 different papers. Only $8 \%$ of the referenced papers ( 68 papers) are shared between at least two publications.

Most Referenced Papers: The most referenced articles of LAK 2013 are presented in Table 1. As can be seen, all of the top-12 papers are specifically Learning Analytics papers, published in previous editions of LAK or in related Learning Technology venues that existed before LAK. This result complements the one found in the previous analysis. Even though small, there is a body of knowledge central to Learning Analytics and new papers in the field use it. The maturity of the field can be judged again by the nature of the most referenced papers. Most are definitions of the concept of Learning Analytics or early examples of its use. This focus of citation on conceptual papers was also found in Dawson et al. (2014). The number of references to article follows a traditional long-tailed distribution.

Most Referenced Authors: The references found in LAK 2013 papers also allow us to find the more relevant scientists in the field, at least from the perspective of this particular conference. The top nine authors can be seen in Table 2. The results, not surprisingly, relate to the general perception of leaders in the field. The distribution of references to authors also follows the long-tailed distribution common to scientific citation.

Bibliographic Coupling Network: Two papers are bibliographically coupled if they both reference the same third paper. The strength of the coupling depends on the number of papers referenced in common. Figure 5 shows a network where each node is a paper published in LAK 2013 and the edges between them represent the strength of their bibliographical coupling. The size of each node represents the number of other papers to which that node is coupled. As Figure 5 shows, most of the papers are coupled to at least one other paper. While still nascent, the strength of the core network (papers 3, 26, $28,31,32,33)^{1}$ seems to validate a common body of knowledge that Learning Analytics considers its own. These papers seem to lay out the bounds of the field. Of the ten disconnected nodes, five are papers ( 7 is a long paper and 15, 30, 38, and 41 are short papers) and five are workshops and panels, which is not surprising since such documents contain few or no references.

\footnotetext{
1 Paper 3: Santos, Verbert, Govaerts, and Duval (2013); paper 26: Clow (2013); paper 28: Dimopoulos, Petropoulou, and Retalis (2013); paper 31: Monroy, Snodgrass Rangel, and Whitaker (2013); paper 32: Dyckhoff, Lukarov, Muslim, Chatti, and Schroeder (2013); paper 33: Camilleri, de Freitas, Montebello, and McDonagh-Smith (2013).
} 
Table 1. References most cited by LAK 2013 papers

Paper Title

\section{Table 1. References most cited by LAK 2013 papers}

\section{Peper Titte}

政

Ferguson, R., \& Buckingham Shum, S. (2012, April). Social learning analytics: Five approaches. Proceedings of the Second International Conference on Learning Analytics and Knowledge (pp. 23-33). ACM.

Ferguson, R. (2012, March). The state of learning analytics in 2012: A review and future challenges. Knowledge Media Institute.

Bienkowski, M., Feng, M., \& Means, B. (2012). Enhancing teaching and learning through educational data mining and learning analytics: An issue brief. US Department of Education, Office of Educational Technology, 1-57.

Buckingham Shum, S., \& Ferguson, R. (2012). Social Learning Analytics. Educational Technology \& Society, 15(3), 3-26.

Arnold, K. E., \& Pistilli, M. D. (2012, April). Course Signals at Purdue: Using learning analytics to increase student success. Proceedings of the Second International Conference on Learning Analytics and Knowledge (pp. 267-270).

Govaerts, S., Verbert, K., Duval, E., \& Pardo, A. (2012, May). The student activity meter for awareness and self-reflection. $\mathrm{CHI}$ '12: Extended Abstracts on Human Factors in Computing Systems (pp. 869-884). ACM.

Arnold, K. E. (2010). Signals: Applying academic analytics. Educause Quarterly, 33(1), n1.

Clow, D. (2012, April). The learning analytics cycle: Closing the loop effectively.

Proceedings of the Second International Conference on Learning Analytics and Knowledge (pp. 134-138). ACM.

Siemens, G. (2012, April). Learning analytics: Envisioning a research discipline and a domain of practice. Proceedings of the Second International Conference on Learning Analytics and Knowledge (pp. 4-8). ACM.

Oblinger, D., \& Campbell, J. (2007). Academic analytics, Educause white paper. Retrieved 20 October 2011.

Elias, T. (2011). Learning analytics: Definitions, processes and potential. Learning, 23, 134-148.

Siemens, G., \& Long, P. (2011). Penetrating the fog: Analytics in learning and education. Educause Review, 46(5), 30-32.

No. of

References

\begin{tabular}{|l|l|}
\hline$g$ & 7 \\
\hline d & 6 \\
\hline S & 6 \\
\hline al & 5 \\
\hline y & 5 \\
\hline y & 5 \\
\hline , & 5 \\
\hline a & 4 \\
\hline d & 4 \\
\hline
\end{tabular}

Table 2. Top Nine Referenced Authors in LAK 2013

\begin{tabular}{|l|c|c|}
\hline \multicolumn{1}{|c|}{ Author } & Times Referenced & No. Papers in which Referenced \\
\hline G. Siemens & 22 & 16 \\
\hline R. Ferguson & 27 & 15 \\
\hline E. Duval & 27 & 13 \\
\hline S. Buckingham Shum & 20 & 11 \\
\hline K. Verbert & 22 & 10 \\
\hline R. S. J. d. Baker & 21 & 8 \\
\hline S. Dawson & 14 & 8 \\
\hline A. Pardo & 11 & 8 \\
\hline K. Koedinger & 11 & 8 \\
\hline
\end{tabular}




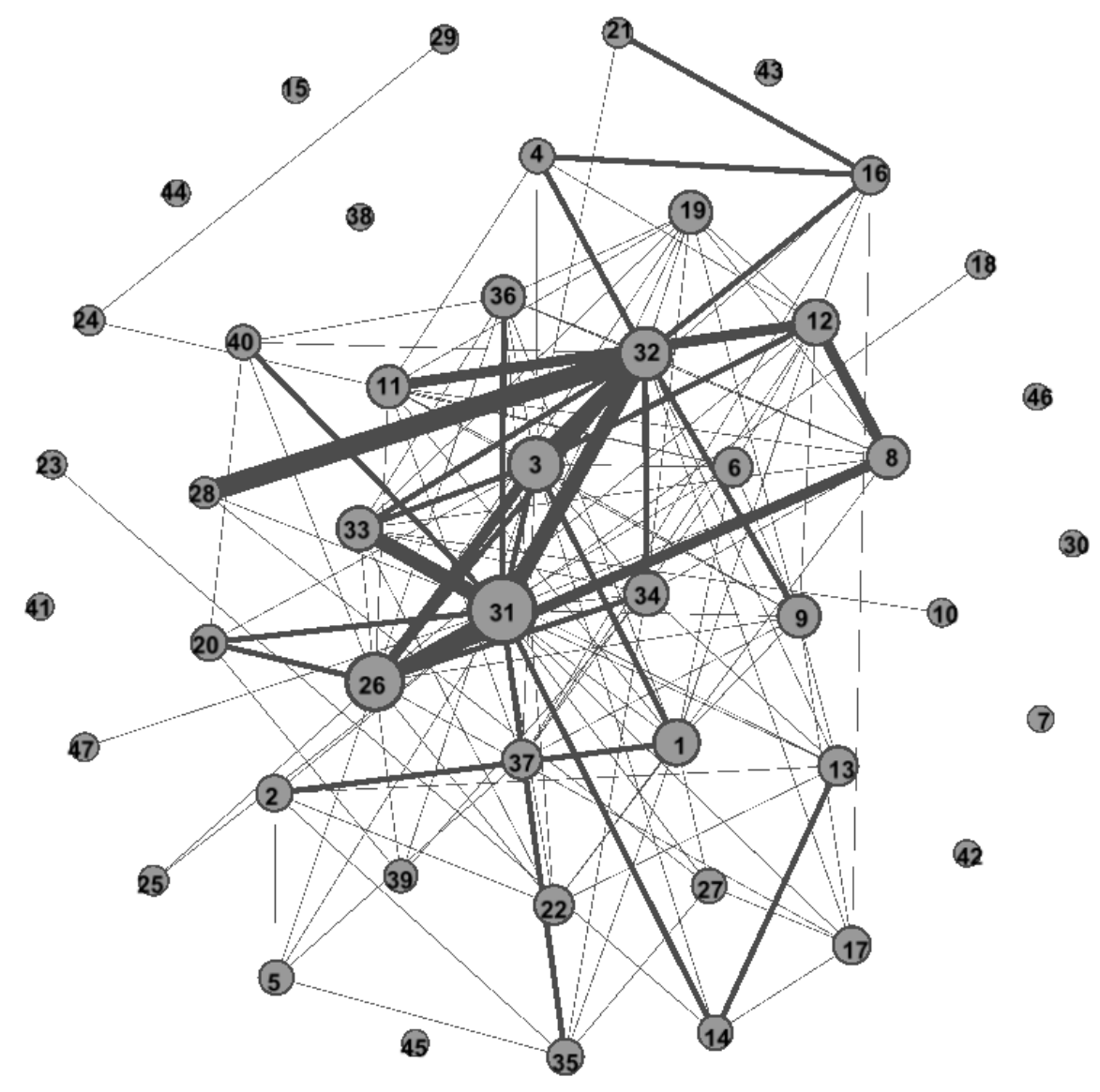

Figure 5. Bibliographic Coupling Network: Each node represents a paper published in LAK 2013

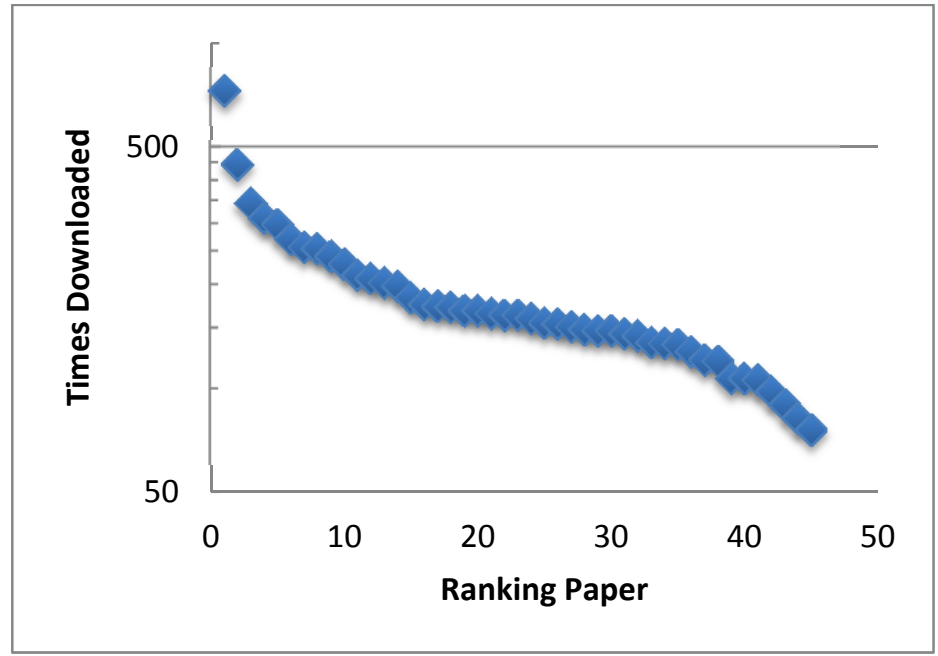

Figure 6. Paper downloads from ACM Digital Library 


\subsection{External Citation Analysis}

While one year on is still too early to determine the relevance of the papers published in LAK 2013 by the number of citations, the number of times they have been accessed or downloaded from the ACM Digital Library could be used as a proxy indication of the impact of the different papers in the field (see Figure 6). The most downloaded paper - "MOOCs and the funnel of participation" (Clow, 2013) - had been downloaded 732 times by the time of this study. The second most downloaded paper "Deconstructing disengagement: Analyzing learner subpopulations in massive open online courses" (Kizilcec, Piech, \& Schneider, 2013) - has been downloaded 444 times. These two papers deal with a trending topic: Massive online open courses (MOOCs). This result suggests that the early visibility of the papers and by proxy, their early impact on the field, is strongly connected to the popularity of the topics they discuss.

\subsection{Word Analysis}

Counting the number of times a word appears in a set of documents usually correlates to the importance of the underlying concept to the topic. The Carrot ${ }^{2}$ clustering engine (Stefanowski \& Weiss, 2003) was used to detect the main words used in LAK 2013 papers and to find related words that appear frequently with those important words. This analysis provides an idea of the main concepts discussed in Learning Analytics papers. Figure 7 presents the seven most used, non-stop words in LAK 2013 documents. The size of each word relates to its relative frequency (number of documents in which the word appears divided by the number of documents) in the document set. Seven words have a relative frequency of larger than 0.1 (10\%): students, data, analytics, learning, use, activity, and education. These words can be considered the ad-hoc definition of Learning Analytics: use of student and activity data to improve learning and educational processes. A more detailed view of the word analysis can be seen in Figure 8, which shows the most common words that appear together with the most frequent words. Here concepts used in Learning Analytics can be found: student performance, student interaction, datasets, linked data, process analytics, learning environments, learning process, collaborative learning, learning activities, activity theory, activity streams, higher education, educational research, etc. Comparing these words to similar analyses for LAK 2011 and LAK 2012 shows some consolidation in concepts (a lower number of frequent terms) and an increase in the richness of concepts (more related words for each frequent word). In summary, the word analysis suggests a conference with increased focus and depth.

\section{CONTENT ANALYSIS}

\subsection{Identified Topics}

The LAK '13 program grouped papers into 14 sessions (Suthers \& Verbert, 2013): reflections on learning analytics, visualization for reflection and awareness, social learning analysis and visualization, communication and collaboration, discourse analytics, behaviour analysis, affect analytics, predictive analytics, sequence analysis, MOOCs, assessment, supporting teachers, challenges, and design briefings.

If the classification had been done without restrictions regarding timetable or session length, these papers could have been clustered into six categories: 


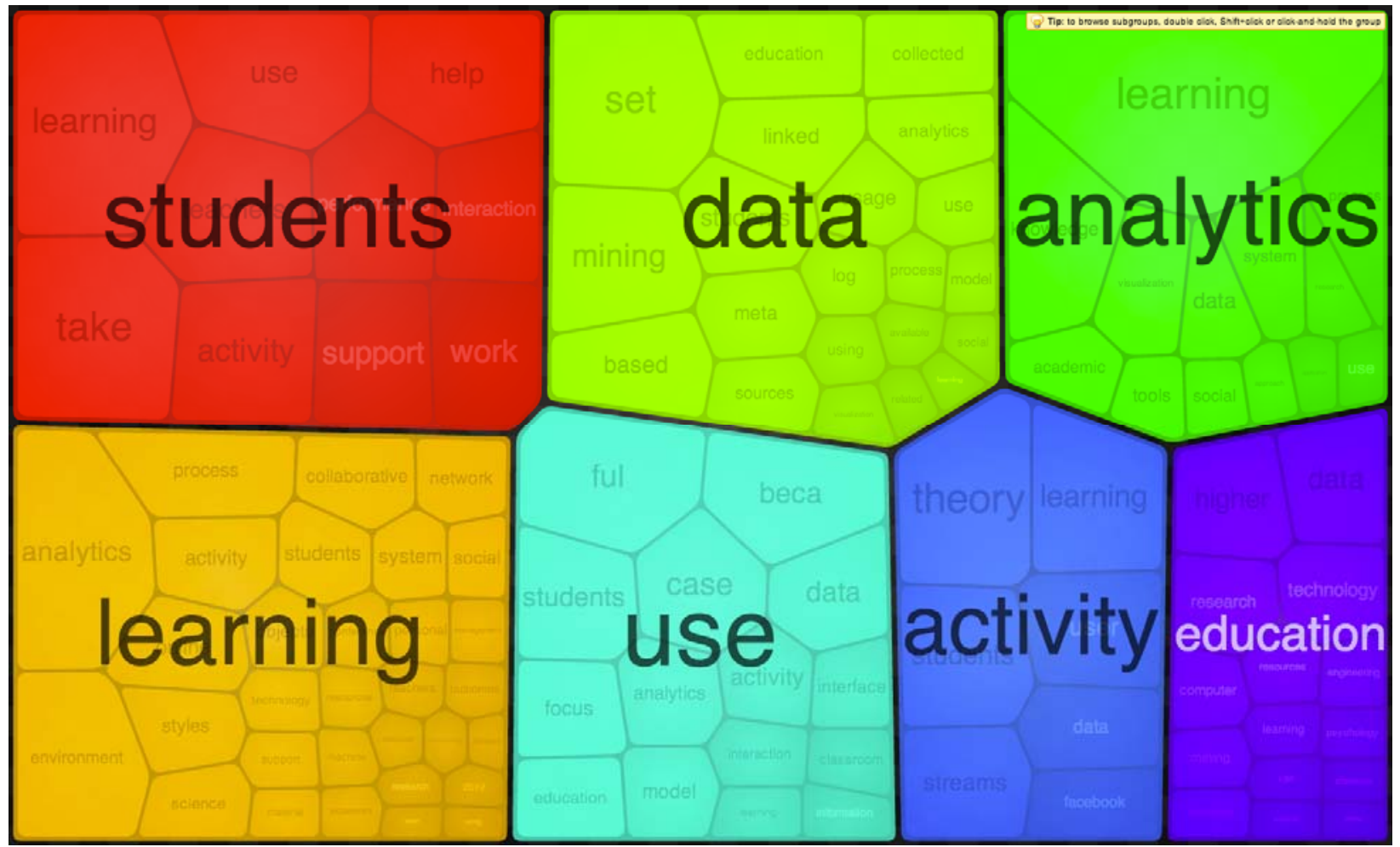

Figure 7. Most frequent words in LAK 2013 papers

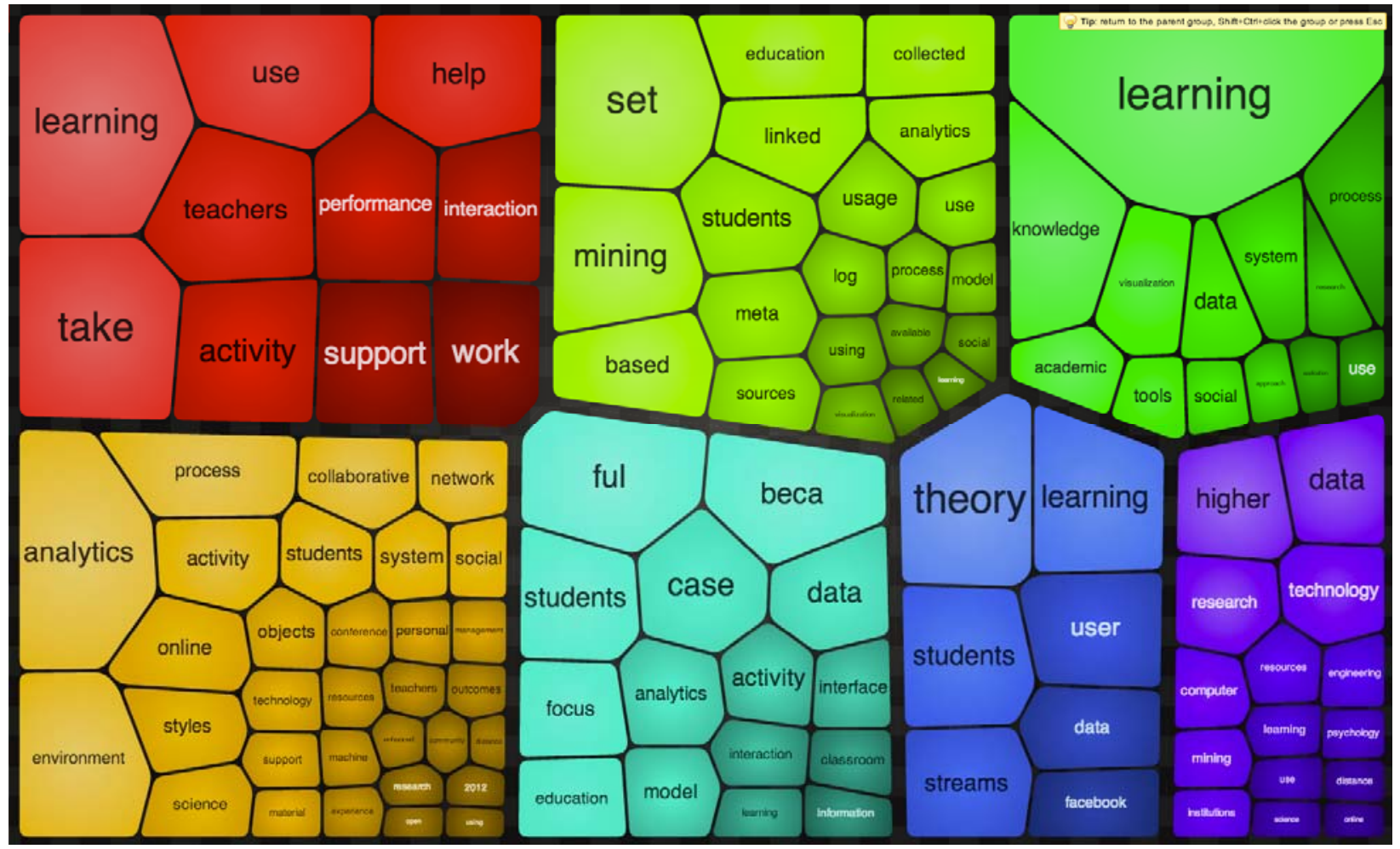

Figure 8. Words related to most frequent words in LAK 2013 papers 
1. Visualization. Papers in this category focus on increasing reflection and awareness through visualization techniques. Dashboard applications are presented as well as evaluation studies that assess the impact of such dashboards on student learning. Visualization methods appear throughout the other categories, reflecting their relevance to multiple stakeholders.

2. Behaviour analysis. The first of four categories of these papers offers advances in making higherlevel inferences from low-level actions by capturing and analyzing different data sources (gesture and object manipulation, eye tracking data, data captured from Kahn academy). A second category focuses specifically on effects; for example, to estimate confidence or level of expertise from eye tracking data. A third, predictive analytics, tries to predict at-risk students and to show the development of new media learning skills from participation in Facebook. A final category focuses on analysis of the sequential structure of student actions; for example, to categorize student trajectories for exploring a game environment on fractions.

3. Social learning analytics. This area combines both analysis and visualization techniques to gain insight into social behaviour. In the first of three sections, research focuses on analysis and visualization of social interactions to make people aware of their social context. In the second collection, communication and collaboration is analyzed, focusing on both reading and writing activities, including analysis of paragraph level revisions and how collaboration forms around topics in collaborative writing. The last section focuses on discourse analytics from diverse perspectives: scientometric path analysis (citation analysis that includes temporality) to model knowledge evolution; a comparative evaluation classification approach for identifying exploratory dialogue; and theoretical reflections on how learning analytics embody assumptions about both our own and learners' epistemologies, with applications for the analysis of user trace data.

4. Applications. Beginning with learning analytics applied to Massive Open Online Courses (MOOCs) in which large numbers of people participate with an open enrollment model, applications of learning analytics form an important topic. Assessment and teacher support - such as by visualizing data collected in real applications for monitoring and direct content development - are both important objectives of several applications.

5. Challenges. This group of papers discusses challenges such as scalable learning analytics, ethics and institutional policies for using student data, and collection and sharing of datasets for research purposes. These challenges include the design and development of architectures for organizing the analytic enterprise across micro and macro levels of activity, and across the various tools used in a collaborative learning environment.

6. Definitional. A few papers reflect on learning analytics itself, including its theoretical and pedagogical assumptions and examination of the identity and interdisciplinary nature of the field.

\subsection{Representative Papers}

In this section, we highlight representative papers that address the identified topics. The papers chosen include those nominated for the best paper award and others representative of their categories. 


\subsubsection{Visualization}

Santos, Verbert, Govaerts, and Duval (2013) present a study that assesses the use of visualizations to support learning analytics. The overall objective is to use learning analytics dashboards that incorporate relevant visualizations to support awareness, self-reflection, and sense-making for learners. Although several learning analytics dashboards have been discussed in recent literature (Verbert et al., 2013), little research has been done to evaluate the usefulness of these dashboards for learners. Santos et al. (2013) present the results of an evaluation study of the StepUp! dashboard, and the extent to which it addresses the issues and needs of learners as collected in brainstorming sessions. The authors then evaluate to what extent the dashboard addresses these issues and needs.

Another example of visualization is the paper by Southavilay, Yacef, Reimann, and Calvo (2013), who visualize document revisions, topic evolution, and collaboration networks based on feedback concerning the individual and collective agency of collaborative writers and their teachers, which leads to the next category of behaviour analysis.

\subsubsection{Behaviour Analysis}

Some papers in this category utilize sequential analysis at granularities ranging from the individual actions of learners to community learning processes over time. For example, main path analysis is a method from sociometrics for identifying key publications in the development of a scientific field by tracing paths in the directed acyclic graph of citations. Halatchliyski, Hecking, Göhnert, and Hoppe (2013), a best paper nominee, apply main path analysis to the evolution of artifacts in a collaboratively edited Wikiversity to analyze the introduction and evolution of ideas in the community. A flexible analytic workbench supports the work. At the other extreme of granularity, which the authors call "nanogenetic analysis," Martin et al. (2013) use keystroke-level data to track and classify student trajectories in the state-space of a game.

Two salient and well-received papers in this area explore alternative data sources for learning analytics based on embodied activity. The paper by Schneider, Abu-El-Haija, Reesman, and Pea (2013), a best paper nominee, also exemplifies sequential analysis at the level of individual actions. Schneider et al. used eye tracking on collaborating dyads and represented gaze location and transitions as graphs. They combined the graphs for each dyad to represent shared gaze. Graphs with denser shared gaze locations and transitions indicate mutual orientation towards the task. Further research is proposed to identify network metrics that can predict task performance. Worsley and Blikstein (2013) present research on how to identify expertise of students automatically from object manipulation data and gestures. More specifically, multimodal learning analytics techniques for understanding and identifying expertise as students engage in a hands-on building activity are presented. The authors were able to identify key elements in how to segment and compress object manipulation codes. In addition, they show how dynamic time warping combined with clustering can be used to classify student expertise accurately. The research outcomes also motivate further promising, but challenging, research in the area of behaviour analysis with a wide variety of sensing devices.

Alternative metrics can also be considered within online environments. Wise, Zhao, and Hausknecht (2013) draw our attention to the importance of "invisible behaviour," such as student message reading, as well as message writing in online forums. They also discuss a framework for applying learning analytics that includes their integration with the goals of learning, student agency in interpreting diverse 
measures, providing time and space for learner reflection on analytics, and supporting discussion between students and instructors as partners.

\subsubsection{Social Learning Analytics}

Social learning analytics (Buckingham Shum \& Ferguson, 2012) is one of the more active areas of research and discussion; the most cited paper at LAK '13 was an overview of the topic (Ferguson \& Buckingham Shum, 2012). Interesting work on social learning analytics, focusing on understanding the literacies embedded in social media participation, was presented by Ahn (2013). The research employed an exploratory factor analysis to examine how raw activity data may group into particular participatory practices, as well as regression models that explore whether these participatory practices predict new media literacy skills. More specifically, data from Facebook was used to examine relationships between the behaviours of learners resulting in a promising approach to identify new media literacy skills related to 21 st century skills. Many papers in behaviour analysis also addressed social learning concerns.

\subsubsection{Applications}

The application of learning analytics in MOOCs is of major interest, and important challenges related to both popularity and low completion rates of learners are a central concern in MOOCs. The highly downloaded short paper by Doug Clow (2013) quantifies the drop-off of activity in three online learning sites. The full paper by Kizilcec, Piech, and Schneider (2013) goes further, presenting a classification method that identifies different engagement trajectories in MOOCs based on learner interaction with video lectures and assessments: "completing," "auditing," "disengaging" and "sampling." With this classifier, the paper posits a promising approach to deconstructing gained disengagement based on interaction data with materials commonly used by MOOCs. The paper also draws our attention to the fact that learners may be accessing MOOCs with different motivations, and that, for many of them, meeting their objectives does not necessarily include completion. At the time of writing, the paper had already been cited 68 times by researchers in the field, illustrating the high potential of this work for the learning analytics field (source: Google Scholar).

\subsubsection{Challenges}

A challenge articulated by several researchers is the collection of datasets that can be shared for research purposes (Drachsler et al., 2010; Verbert, Manouselis, Drachsler, Duval, 2012). The overall objective is to collect data captured in real-life settings, from different learning environments, and to make such data available for researchers to enable comparison of research results. Niemann, Wolpers, Stoitsis, Chinis, \& Manouselis (2013) present research regarding interchanging data collected from different learning environments. The authors first studied the data types and formats that learning environments use to represent and store learner data. In addition, they developed crosswalks between different schemas, so that datasets can be combined. The paper presents interesting issues that must be addressed before aggregated sets of learner data can actually be used to support learning analytics research.

\subsubsection{Reflections}

Two of the LAK '13 best paper nominees offered reflections on the field itself. A thought provoking paper by Knight, Buckingham Shum, and Littleton (2013) examined the relationships between pedagogy, assessment, and epistemology, challenging us to identify where we stand in our own learning analytic practice. The authors outline the analytic implications of several established pedagogic approaches; for example, that "transactional approaches may emphasise use of facts; constructivist the broad (and 
contextual) application of skills; subjectivist the self-efficacy and motivators of students; apprenticeship the dynamic practical based learning which may occur through high level membership of communities of practice; connectivism the ability of students to build up, link and curate their knowledge 'networks.'" Thus, reasoning in converse, learning analytics are not neutral but may imply or encourage certain pedagogical views. The authors go further to argue that learning analytics embody epistemological assumptions about the nature of knowledge in how they approach the assessment of knowledge. Becoming aware of these epistemological assumptions is consequential because learning analytics can be used to perpetuate assessment regimes "detrimental to the wider enterprise of education," or alternatively assessment regimes that emphasize learner agency and the contextualized nature of knowledge. The paper is recommended for those wanting to approach their analytic practice in a deliberate and reflective manner.

Moving now to an even broader perspective, Balacheff and Lund (2013), grapple with the question of how multiple disciplines come together in learning analytics, and its relation to other research areas, such as educational data mining. In multidisciplinarity, the subject of study is approached from each disciplinary perspective without theoretical, conceptual, or methodological integration, while interdisciplinary research involves such integration. A bridge between the two may be found in strategies of "productive multivocality" (Suthers, Lund, Rose, Teplovs, \& Law, 2013), methods of bringing together the various "voices" of different theoretical and methodological traditions in dialogues that not only provide different points of view on the subject but also expose assumptions and make epistemological positions explicit. Balacheff and Lund (2013) call for examining and making explicit the "problématiques" of learning analytics: the coherent frameworks by which we express problems and why they are interesting to solve along with the approaches for solving them. They challenge us to confront "the different understandings of Learning Analytics, without necessarily choosing any one particular definition as the one that is destined to become canonical."

\section{CONCLUSIONS}

The main findings of the analyses conducted on LAK ' 13 can be summarized as follows:

- LAK '13 was the venue of an open and international community of researchers. This community currently consists of a core of 40 researchers that attracts an orbit of 100 additional authors.

- The statistical distributions of the author community of LAK '13 are in line with that of other scientific communities.

- The body of knowledge central to learning analytics is still small but already shows signs of consolidation.

- Five main topics have been identified in the LAK '13 program - visualization, behaviour analysis, social learning analytics, learning analytics for MOOCs, and learning analytics issues (ethical, scalability, etc.) - as well as a sixth topic of reflecting on the field itself.

- Learning analytics is at a crucial stage in its development that calls for individual and collective reflection and dialogue to arrive at an understanding of the field. This is not necessarily a single core definition, but rather a locus for productive dialogue and collaboration between multiple theoretical, methodological, and practical perspectives concerning what problems are important to solve and how the analytics we are promoting reflect our epistemological assumptions and pedagogical stances. 
(2014). Analysis and Reflections on the Third Learning Analytics and Knowledge Conference (LAK 2013). Journal of Learning Analytics, 1(2), 5-22.

This kind of analysis should be performed periodically to gain insight on the evolution of the field, as well as to confirm the healthy status of its surrounding community.

\section{ACKNOWLEDGMENTS}

Katrien Verbert is a Post-doctoral fellow of the Research Foundation - Flanders (FWO)

\section{REFERENCES}

Ahn, J. (2013). What can we learn from Facebook activity? Using social learning analytics to observe new media literacy skills. Proceedings of the Third International Conference on Learning Analytics and Knowledge (LAK'13), 8-12 April 2013, Leuven, Belgium (pp. 135-144). New York: ACM.

Arnold, K. E. (2010). Signals: Applying academic analytics. Educause Quarterly, 33(1), n1.

Arnold, K. E., \& Pistilli, M. D. (2012, April). Course Signals at Purdue: Using learning analytics to increase student success. Proceedings of the Second International Conference on Learning Analytics and Knowledge (LAK'12), 29 April-2 May, Vancouver, BC, Canada (pp. 267-270). New York: ACM.

Balacheff, N., \& Lund, K. (2013). Multidisciplinarity vs. Multivocality: The case of "Learning Analytics." Proceedings of the Third International Conference on Learning Analytics and Knowledge (LAK '13), 8-12 April 2013, Leuven, Belgium (pp. 5-13). New York: ACM.

Bienkowski, M., Feng, M., \& Means, B. (2012). Enhancing teaching and learning through educational data mining and learning analytics: An issue brief. US Department of Education, Office of Educational Technology, Washington, D.C., 1-57.

Buckingham Shum, S., \& Ferguson, R. (2012). Social learning analytics. Educational Technology and Society, 15(3), 3-26.

Camilleri, V., de Freitas, S., Montebello, M., \& McDonagh-Smith, P. (2013). A case study inside virtual worlds: Use of analytics for immersive spaces. Proceedings of the Third International Conference on Learning Analytics and Knowledge (LAK'13), 8-12 April 2013, Leuven, Belgium (pp. 230-234). New York: ACM.

Campbell, J. P., DeBlois, P. B., \& Oblinger, D. G. (2007). Academic analytics: A new tool for a new era. Educause Review, 42(4), 40.

Clow, D. (2012, April). The learning analytics cycle: Closing the loop effectively. Proceedings of the Second International Conference on Learning Analytics and Knowledge (LAK '12), 29 April-2 May, Vancouver, BC, Canada (pp. 134-138). New York: ACM.

Clow, D. (2013). MOOCs and the funnel of participation. Proceedings of the Third International Conference on Learning Analytics and Knowledge (LAK '13), 8-12 April 2013, Leuven, Belgium (pp. 185-189). New York: ACM.

Dawson, S., Gašević, D., Siemens, G., \& Joksimovic, S. (2014). Current state and future trends: A citation network analysis of the learning analytics field. Proceedings of the Fourth International Conference on Learning Analytics and Knowledge (LAK'14). 24-28 March, Indianapolis, Indiana, USA (pp. 231-240). New York: ACM.

Ding, Y., Chowdhury, G. G., \& Foo, S. (2001). Bibliometric cartography of information retrieval research 
(2014). Analysis and Reflections on the Third Learning Analytics and Knowledge Conference (LAK 2013). Journal of Learning Analytics, 1(2), 5-22.

by using co-word analysis. Information Processing \& Management, 37(6), 817-842.

Drachsler, H., Bogers, T., Vuorikari, R., Verbert, K., Duval, E., Manouselis, N., Beham, G., Stern, H., Lindstaedt, S., Friedrich, M., \& Wolpers, M. (2010). dataTEL: Issues and Considerations regarding Sharable Data Sets for Recommender Systems in Technology Enhanced Learning. Procedia Computer Science, 1(2): 2849-2858.

Dimopoulos, I., Petropoulou, O., \& Retalis, S. (2013). Assessing students' performance using the learning analytics enriched rubrics. Proceedings of the Third International Conference on Learning Analytics and Knowledge (LAK'13), 8-12 April 2013, Leuven, Belgium (pp. 195-199). New York: ACM.

Dyckhoff, A. L., Lukarov, V., Muslim, A., Chatti, M. A., \& Schroeder, U. (2013). Supporting action research with learning analytics. Proceedings of the Third International Conference on Learning Analytics and Knowledge (LAK '13), 8-12 April 2013, Leuven, Belgium (pp. 220-229). New York: ACM.

Elias, T. (2011). Learning analytics: Definitions, processes and potential. Learning, 23, 134-148.

Ferguson, R. (2012, March). The State of Learning Analytics in 2012: A Review and Future Challenges. Technical Report KMI-12-01. Knowledge Media Institute, The Open University, Milton Keynes, United Kingdom. http://kmi.open.ac.uk/publications/techreport/kmi-12-01

Ferguson, R., \& Buckingham Shum, S. (2012). Social learning analytics: Five approaches. Proceedings of the Second International Conference on Learning Analytics \& Knowledge (LAK '12), 29 April-2 May, Vancouver, BC, Canada (pp. 23-33). New York: ACM.

Govaerts, S., Verbert, K., Duval, E., \& Pardo, A. (2012, May). The student activity meter for awareness and self-reflection. $\mathrm{CHI}$ '12: Extended Abstracts on Human Factors in Computing Systems (pp. 869-884). New York: ACM.

Halatchliyski, I., Hecking, T., Göhnert, T., \& Hoppe, H. U. (2013). Analyzing the flow of ideas and profiles of contributors in an open learning community. Proceedings of the Third International Conference on Learning Analytics and Knowledge (LAK '13), 8-12 April 2013, Leuven, Belgium (pp. 66-74). New York: ACM.

Hood, W. W., \& Wilson, C. S. (2001). The literature of bibliometrics, scientometrics, and informetrics. Scientometrics, 52(2), 291-314.

Kessler, M. M. (1963). Bibliographic coupling between scientific papers. American documentation, 14(1), 10-25.

Kizilcec, R. F., Piech, C., \& Schneider, E. (2013). Deconstructing disengagement: Analyzing learner subpopulations in massive open online courses. Proceedings of the Third International Conference on Learning Analytics and Knowledge (LAK '13), 8-12 April 2013, Leuven, Belgium (pp. 170-179). New York: ACM.

Knight, S., Buckingham Shum, S., \& Littleton, K. (2013). Epistemology, pedagogy, assessment and learning analytics. Proceedings of the Third International Conference on Learning Analytics and Knowledge (LAK'13), 8-12 April 2013, Leuven, Belgium (pp. 75-84). New York: ACM.

Leydesdorff, L., \& Wagner, C. S. (2008). International collaboration in science and the formation of a core group. Journal of Informetrics, 2(4), 317-325.

Martin, T., Aghababyan, A., Pfaffman, J., Olsen, J., Baker, S., Janisiewicz, P., Phillips, R., \& Petrick Smith, 
(2014). Analysis and Reflections on the Third Learning Analytics and Knowledge Conference (LAK 2013). Journal of Learning Analytics, 1(2), 5-22.

C. (2013). Nanogenetic learning analytics: Illuminating student learning pathways in an online fraction game. Proceedings of the Third International Conference on Learning Analytics and Knowledge (LAK '13), 8-12 April 2013, Leuven, Belgium (pp. 165-169). New York: ACM.

Monroy, C., Snodgrass Rangel, V., \& Whitaker, R. (2013). STEMscopes: Contextualizing learning analytics in a K-12 science curriculum. Proceedings of the Third International Conference on Learning Analytics and Knowledge (LAK'13), 8-12 April 2013, Leuven, Belgium (pp. 210-219). New York: ACM.

Niemann, K., Wolpers, M., Stoitsis, G., Chinis, G., \& Manouselis, N. (2013, April). Aggregating social and usage datasets for learning analytics: Data-oriented challenges. Proceedings of the Third International Conference on Learning Analytics and Knowledge (LAK '13), 8-12 April 2013, Leuven, Belgium (pp. 245-249). New York: ACM.

Oblinger, D., \& Campbell, J. (2007). Academic analytics, Educause white paper. Retrieved 20 October 2011 from https://net.educause.edu/ir/library/pdf/pub6101.pdf

Santos, J. L., Verbert, K., Govaerts, S., \& Duval, E. (2013). Addressing learner issues with StepUp! An evaluation. Proceedings of the Third International Conference on Learning Analytics and Knowledge (LAK'13), 8-12 April 2013, Leuven, Belgium (pp. 14-22). New York: ACM.

Schneider, B., Abu-El-Haija, S., Reesman, J., \& Pea, R. (2013). Toward collaboration sensing: Applying network analysis techniques to collaborative eye-tracking data. Proceedings of the Third International Conference on Learning Analytics and Knowledge (LAK'13), 8-12 April 2013, Leuven, Belgium (pp. 107-111). New York: ACM.

Siemens, G. (2012, April). Learning analytics: Envisioning a research discipline and a domain of practice. Proceedings of the Second International Conference on Learning Analytics and Knowledge (LAK '12), 29 April-2 May, Vancouver, BC, Canada (pp. 4-8). New York: ACM.

Siemens, G., \& Long, P. (2011). Penetrating the fog: Analytics in learning and education. Educause Review, 46(5), 30-32.

Southavilay, V., Yacef, K., Reimann, P., \& Calvo, R. A. (2013). Analysis of collaborative writing processes using revision maps and probabilistic topic models. Proceedings of the Third International Conference on Learning Analytics and Knowledge (LAK '13), 8-12 April 2013, Leuven, Belgium (pp. 38-47). New York: ACM.

Stefanowski, J., \& Weiss, D. (2003). Carrot ${ }^{2}$ and language properties in web search results clustering. In E. Menasalvas, J. Segovia, P. S. Szczepaniak (Eds.), Advances in Web Intelligence (pp. 240-249). Lecture Notes in Computer Science Volume 2663. Berlin/Heidelberg: Springer.

Suthers, D. D., Lund, K., Rosé, C. P., Teplovs, C., \& Law, N. (2013). Productive Multivocality in the Analysis of Group Interactions. New York: Springer.

Suthers, D. D., \& Verbert, K. (2013). Learning analytics as a "middle space." In D. D. Suthers, K. Verbert, E. Duval, \& X. Ochoa (Eds.), Proceedings of the Third International Conference on Learning Analytics and Knowledge (LAK'13), 8-12 April, 2013, Leuven, Belgium (pp. 1-4). New York: ACM.

Tinto, V. (1987). Leaving college: Rethinking the causes and cures of student attrition (2nd ed.). Chicago, IL: University of Chicago Press.

Verbert, K., Manouselis, N., Drachsler, H., \& Duval, E. (2012). Dataset-driven research to support learning and knowledge analytics. Educational Technology and Society, 15(3), 133-148. 


\section{JOURNAL OF LEARNING ANALYTICS}

(2014). Analysis and Reflections on the Third Learning Analytics and Knowledge Conference (LAK 2013). Journal of Learning Analytics, 1(2), 5-22.

Verbert, K., Govaerts, S., Duval, E., Santos, J. L., Van Assche, F., Parra, G., \& Klerkx, J. (2013). Learning dashboards: An overview and future research opportunities. Personal and Ubiquitous Computing (PUC) Journal, 16 pages, Springer.

Wise, A. F., Zhao, Y., \& Hausknecht, S. N. (2013). Learning analytics for online discussions: A pedagogical model for intervention with embedded and extracted analytics. Proceedings of the Third International Conference on Learning Analytics and Knowledge (LAK'13), 8-12 April 2013, Leuven, Belgium (pp. 48-56). New York: ACM.

Worsley, M., \& Blikstein, P. (2013). Towards the development of multimodal action based assessment. Proceedings of the Third International Conference on Learning Analytics and Knowledge (LAK '13), 8-12 April 2013, Leuven, Belgium (pp. 94-101). New York: ACM. 